\title{
College Students' Perceptions of Stress and Coping Mechanisms
}

\author{
Kelsey M. Gallagher ${ }^{1}$, Tiara R. Jones ${ }^{1}$, Nicole V. Landrosh ${ }^{1}$, Samuel P. Abraham ${ }^{1} \&$ Deborah R. Gillum ${ }^{1}$ \\ ${ }^{1}$ Bethel University School of Nursing, Mishawaka, Indiana, USA \\ Correspondence: Samuel P. Abraham, Bethel University School of Nursing, 1001 Bethel Circle, Mishawaka, \\ Indiana, 46545, USA. E-mail: samuel.abraham@betheluniversity.edu
}

Received: May 27, 2019

doi:10.20849/jed.v3i2.600
Accepted: June 7, 2019

Online Published: June 23, 2019

URL: https://doi.org/10.20849/jed.v3i2.600

\begin{abstract}
Background: Typical college students experience stressors every day. Purpose: The purpose of this study was to determine college students' perceptions of stress and coping mechanisms. Method: A quantitative, non-experimental, cross-sectional, descriptive research design was used to assess students' perception of stress and coping mechanisms. To collect data, a survey tool was used to answer 6 demographic and twenty-five survey items on a 4-point Likert-type scale. Two central research questions guided the study: (1) What are college students' perceptions of stress? and (2) What are college students' perceptions of coping mechanisms? Results: The responses to these questions were analyzed and the implications are discussed. Conclusion: College students agree that college life is stressful and that their level of stress increases significantly before exams. In addition, students reported that expectations to excel in classes cause additional stress. Students reported a variety of coping mechanisms, including listening to music, socializing with friends/family, and sitting alone in a quiet place.
\end{abstract}

Keywords: stress, coping mechanisms, college students, students' perceptions of stress, academic stress, personal stress

\section{Introduction}

At some point in life, every person faces stress. The National Institute for Mental Health (NIMH, 2016) states, "stress is how the brain and body respond to any demand" (para. 1). For college students, stress comes in many shapes and forms. College students are faced with a variety of stressors, including academics, finances, increased pressure to perform well, and personal relationships (Deasy, Coughlan, Pironom, Jourdan, \& McNamara, 2015). Some stress is positive, and some are negative. The Center for Disease Control (CDC, 2017) stated, "stress can be harmful when it is prolonged" (para. 3). If stress is severe, it can make one feel overwhelmed and out of control. The purpose of this study was to determine college students' perception of stress and coping mechanisms.

\subsection{Background}

The typical college student experiences stress every day, stemming from one or more sources, which can have a serious impact on a person's overall health. Stress and lack of coping mechanisms create a problem with college students that may be detrimental to their success and overall health. This is experienced when a college student is overwhelmed with stress and they do not properly deal with it. This may be from lack of knowledge or pure inability to cope because the amount of stress may be debilitating. Peer, Hillman, and Van Hoet (2015) found that stress negatively affects the mental health of emerging adults. Furthermore, when students are unable to properly cope with stress, it decreases their likelihood to graduate (Eyong, 2013).

Based on experience, observation, and the literature review, a gap in knowledge of stress-related coping mechanisms in college students was noted. The following research may help bridge this gap. The results of this research may be helpful in creating effective interventions to counter the negative effects stress has on students in higher education.

\subsection{Research Questions}

The following two central research questions guided this study:

RQ1: What are college students' perceptions of stress?

RQ2: What are college students' perceptions of coping mechanisms? 


\section{Review of Literature}

A thematic review of the literature is discussed below. Search procedures included the use of the Cumulative Index of Nursing and Applied Health Literature (CINAHL) and EBSCOhost databases, in addition to Google Scholar. Keywords used included stress, coping mechanisms, college students, students' perceptions of stress, academic stress, and personal stress. Studies were peer-reviewed articles primarily published between 2015 to 2018.

\subsection{Stress Among College Students}

Jennings, Henderson, Erla, Abraham, and Gillum (2018) affirmed "college students are vulnerable to stress and poor coping habits" (p. 248). Stress is an unavoidable part of life, but college students have a unique set of stressors that commonly affect them. In a recent survey conducted by the American College Health Association (ACHA, 2017), $41.5 \%$ of college students reported having a "more than average" level of stress, and $12.5 \%$ reported having a "tremendous" level of stress (p. 16). Dexter, Huff, Rudecki, and Abraham (2018) reported "potential stressors on a college campus are changes in social activities, conflicts with a roommate, new friends, girlfriend or boyfriend, changes in sleep habits, and financial difficulties" (p. 1).

\subsection{Coping Mechanisms Among College Students}

When people face stress, they typically use some form of coping mechanism to combat and lower their stress. Coiro, Bettis, and Compas (2017) explained that successful coping involves, accurate understanding of the level of control over the stressor as well as selecting an appropriate coping mechanism to handle the stressor. It is important not only that college students are selecting appropriate coping mechanisms to use, but that they are also assessing their stress and their ability to handle it on their own.

The absence or presence of coping mechanisms among students affects mental health as well. Coiro et al. (2017) reported that coping mechanisms "have been identified as a key mechanism linking perceived stress and stressful life events to the development of mental health problems" (p. 177). Anxiety, depression, and somatization symptoms are common among students who have a higher perceived level of stress (Coiro et al., 2017). Students who reported high levels of psychological stress were more likely to cope negatively with the use of tobacco, physical inactivity, and poor diet, including an increase in the consumption of convenience foods (Deasy et al., 2015, p. 82).

\subsection{Students' Perception of Stress}

The way in which a person perceives stress is an important factor in how they handle their stress. When students fail to understand it, it can become more difficult to cope with stress. In Dexter et al. (2018) study, students agreed most commonly with the statement "creating better health in one area of my life spills into other areas of my life" when asked to respond to statements about their perceptions' of stress in their lives (p. 3). Students also acknowledged that stress affected multiple areas of their lives and by bettering one area, their stress levels can also decrease. In addition, Saleh, Camart, and Romo (2017) reported a correlation "between perceived stress and factors that could be considered as 'negative' ones, such as psychological distress and its four factors...including somatic symptoms, anxiety and insomnia, social dysfunction and severe depression" (p. 3).

Shatkin et al. (2016) studied the impact of a risk and resilience (R\&R) course on stress, coping skills, and cognitive style among college students. The study compared 36 undergraduate students to 62 students enrolled in a psychopathology course. Undergraduate students learned about risk-taking behaviors, decision-making, and coping skills. At the end of the course, the $R \& R$ students reported improvements in stress, coping and dysfunctional attitudes (Shatkin et al., 2016).

\subsection{Personal Stress}

Hubbard, Reohr, Tolcher, and Downs (2018) identified both intrapersonal and interpersonal stressors that college students may face. Intrapersonal stressors include "personal appearance, self-esteem, body image, and lack of confidence" (p. 297). Interpersonal factors may include relationships with family members, friends, coworkers and roommates; health problems or death of a family member, partner, or friend; and experiencing discrimination (Hubbard et al., 2018).

Personal stress sources vary from person to person. Going to college is a stressful time for many people. Coiro et al. (2017) listed "diminished contact with family members, interpersonal stressors with roommates and romantic partners, and for many students, financial stress" as potential sources of personal stress (p. 177). Holinka (2015) added, "the most common personal stressors identified by college students were developing a future career plan, followed by finances, interpersonal relationships, personal appearance, intimate relationships, personal 
achievement and goal setting" (p. 301).

Students must learn how to handle their personal stressors in a new setting, which can be a difficult task. Personal stress can be associated with higher self-reported symptoms of depression, anxiety, and somatization. In addition, students who report higher levels of stress tend to use less primary and secondary coping mechanisms (Coiro et al., 2017).

\subsection{Academic Stress}

In addition to the personal stressor students face in college, they must adjust to new academic demands and the heavy workload of exams and assignments. Perhaps the most challenging adjustment comes from the new demand of an increased academic workload. The ACHA (2017) reported 47.5\% of students claimed academic stressors to be "traumatic or very difficult to handle" (p. 15). Holinka (2015) argued, "the most frequently reported academic stressors specifically were grades and competition, career and future success, too many demands and meeting deadlines, interpersonal issues in school, and issues related to taking classes and selecting majors" (p. 301).

College students are at an age that makes them more susceptible to stress-related illnesses. Ribeiro et al. (2018) suggested, "the academic period involves the employment of time and financial resources by the students, without guarantees of a satisfactory return" (p. 75). Stress and anxiety from the academic setting can lead to poor academic performance (Ribeiro et al., 2018).

\subsection{Summary of the Literature Review}

The literature review examined published research regarding stress, perception of stress, and coping mechanisms among college students. Based on the review, academic stressors and personal stressors are caused by various factors and the coping mechanisms differ. Though there were multiple studies on stress and coping, stress and coping mechanisms among Christian college students were at a minimum indicating a gap and the need for this study. This study may help bring more insight into this important issue and add to the literature.

\subsection{Definition of Terms}

In this study, stress is defined as a response or reaction that the body experiences when faced with a demand or threat. In other words, it is the body's natural defense mechanism. Coping mechanisms are defined as the ability to use one's own efforts, to solve personal problems, to manage stress or conflict. The term college students refer to individuals 18-years-old or older who are enrolled at the college. Students' perception of stress is defined as their thoughts and feelings about the response or reaction their body experiences when faced with a demand or threat. Academic stress is defined as the body's response to course-related demands that exceed adaptive capabilities of students. Personal stress is referred to as the body's response to a demand or expectation from an external environment that exceeds adaptive capabilities of an individual.

\section{Methodology}

\subsection{Design}

This was a quantitative, non-experimental, descriptive, cross-sectional study. Participation was voluntary. A survey was used to answer 6 demographic questions, 10 survey items about stress, and 15 survey items about coping mechanisms based on a 4-point Likert-type scale. Approval from the Institutional Review Board was obtained prior to conducting the study. The researchers for this study completed the National Institute of Health (NIH) online training program entitled "Protecting Human Research Participants." The researchers had provided information regarding the Wellness Center in case a participant needed a referral because of increased stress or decreased coping mechanism.

\subsection{Population and Sampling}

Both male and female students from the college, ages 18 years and older, were sampled. Participants were given instructions and informed consent to sign prior to completing the survey. Participants were informed of the right to withdraw consent for participation at any time. Participants were ensured that confidentiality would be kept at all times. The sample size was 120 students. All students, excluding senior nursing students, were asked to participate. Convenience sampling was used.

\subsection{Geographic Location}

This college is an educational institution located in northern Indiana. Students were surveyed on the college campus outside of the Dining Commons. Permission to conduct the research in this location was obtained. This location was suitable because of convenience. 


\subsection{Plan for Data Collection and Analysis}

A table was set up at the Dining Commons where students were asked to participate. One hundred and twenty students were surveyed. Store bought candy was offered as a token of gratitude for participating in the study.

After data collection, the information was documented in Excel. Calculation of the demographics was completed by measuring the frequency [f] and the percentage [\%] from the participants of the survey. The mean and standard deviation were calculated for the survey items. Consent was collected from all the participants and was kept separate from the survey sheets.

\subsection{Survey Instrument and Validity}

The survey was developed after a thorough review of the literature. The survey was designed with six demographic statements. Items 1 through 10 addressed stress among college students. The participants selected if they strongly disagree (1), disagree (2), agree (3), or strongly agree (4). Items 11 through 25 asked about coping mechanisms, to which the respondents selected if they use never (1), rarely (2), often (3), or always (4). This was a newly developed survey tool, which had not obtained validity or reliability. This survey was sent to two peers and two professors to obtain face-validity.

\subsection{Informed Consent}

Each participant received an informed consent to sign before participating in the study. Before giving the informed consent, an explanation of the study was discussed with each participant. Participants were reminded that consent to participate may be withdrawn at any point during the survey without any repercussion. Participants were ensured that there were no foreseeable risks in participating in the survey and that results from the survey would be beneficial in learning about college students' perception on stress and coping mechanisms. The participants were informed that participation would take about five minutes of their time. Participants were then able to ask questions before beginning the survey.

Each participant received two copies of the informed consent: one for their records and one that was signed and returned to researchers. All signed informed consents were placed in a manila envelope to maintain confidentiality. Once the signed informed consent was collected from the participant, the survey was distributed to the participant. When a participant turned in a finished survey, store-bought candy was offered as a token of gratitude for participating. The surveys were kept in a second manila envelope to ensure confidentiality.

All collected data for this research was submitted to the School of Nursing to be stored electronically for three years. The School of Nursing staff scanned the data into the computer and stored it on discs in a locked cabinet in a locked storage room. Only the nursing administrators or the research coordinators have access to the stored records.

\section{Results}

The literature review that was previously conducted was the base knowledge for analyzing the results of this study. The purpose of this study was to determine college students' perceptions of stress and coping mechanisms. There were a variety of perceptions from the participants.

\subsection{Research Questions}

RQ 1: What are college students' perceptions of stress?

RQ 2: What are college students' perceptions of coping mechanisms?

\subsection{Data Collection}

Data collection took place outside the Dining Commons. The population that was surveyed only represented the students who used the Dining Commons during their lunch period. Students were offered store bought candy as an incentive to completing the survey. Paper surveys and consent forms were handed to students who were willing to participate and complete the survey. Prior to completing the survey and signing the informed consent, each participant was informed of the purpose of the study and that all responses would be kept confidential. In order to maintain privacy, the participants were instructed not to write their names on the survey. The surveys and consent forms were then collected and placed into separate folders to maintain confidentiality.

After all data were collected, the results were tallied and organized into an Excel spreadsheet. All surveys were examined for completeness prior to submitting final results to the Excel spread sheet. Demographic data was calculated using frequency and percentage. Mean and standard deviation were calculated for survey statements. The higher the mean value represented a strong agreement with a survey statement. For each statement, the standard deviation was calculated to show the variation within the set of data. A larger standard deviation 
represented a greater variation in the participants' answers. Results of the data collected indicated the perceptions of stress and coping mechanisms for this group.

\subsection{Participants' Demographic Characteristics}

Table 1. Descriptive statistics for participant demographics and background

\begin{tabular}{lll}
\hline Variable & $f$ & $\%$ \\
\hline Age Range & 51 & 42.5 \\
$18-19$ & 47 & 39.1 \\
$20-21$ & 20 & 16.7 \\
$22-23$ & 2 & 1.7 \\
24 and older & & \\
Gender & 58 & 48.3 \\
Male & 62 & 51.7 \\
Female & & \\
Academic Year & 43 & 35.8 \\
Freshman & 19 & 15.8 \\
Sophomore & 32 & 26.7 \\
Junior & 26 & 21.7 \\
Senior & & 51.7 \\
Work Hours & 62 & 37.5 \\
Less than 10 & 45 & 6.7 \\
$11-20$ & 8 & 1.7 \\
$21-30$ & 2 & 2.5 \\
$31-40$ & 3 & \\
$40+$ & & 2.5 \\
Credit Hours & 3 & 97.5 \\
Less than 12 & 117 & 16.7 \\
12 or more & &
\end{tabular}

Note. $(\mathrm{N}=120)$.

The participants in this study were college students, ages 18 and older. One hundred and twenty students participated and correctly completed the study. Table 1 contains the demographic statistics of the participants. The table includes age range, gender, academic year, hours worked per week, academic credit hours, and a yes or no question pertaining to if the participant received financial aid for tuition.

Out of the 120 participants, the most common age range was 18-19-year-olds with 51 participants (42.5\%). Twenty to twenty-one year-olds were close with 47 (39.1\%) participating, followed by 22-23 year-olds with 20 $(16.7 \%)$, and 2 participants (1.7\%) for ages 24 and older. There were $58(48.3 \%)$ male participants and 62 $(51.7 \%)$ female participants. There was a mix of all academic years within the population sample, freshman (35.8\%), sophomores (15.8\%), juniors (26.7\%), and seniors (21.7\%). Many of the participants stated that they work less than ten hours per week (51.7\%). Most of the participants was classified as a full-time student being enrolled in 12 credit hours or more (97.5\%). Many of the participants selected "yes" to receiving financial aid $(83.3 \%)$. 


\subsection{Item Set Description}

Table 2. College students' perceptions of stress

\begin{tabular}{lll}
\hline Variable & $M$ & $S D$ \\
\hline College life is stressful. & 3.39 & 0.52 \\
My level of stress increases significantly before exams. & 3.18 & 0.73 \\
Expectations to excel in classes causes additional stress. & 3.14 & 0.76 \\
I feel stressed out by my academic workload. & 3.03 & 0.72 \\
I feel stressed out by personal factors. & 2.95 & 0.77 \\
I can effectively manage my stress using coping mechanisms. & 2.85 & 0.69 \\
Procrastination plays a big part in my stress level. & 2.68 & 0.94 \\
Stress from my academics affects my concentration while studying. & 2.66 & 0.77 \\
& & \\
My personal stressors affect my academic performance. & 2.57 & 0.80 \\
I struggle to balance my personal stress and my academic stress. & 2.47 & 0.80 \\
\hline
\end{tabular}

Note. $(\mathrm{N}=120)$. Items were rated on a 4-point Likert-type scale ranging from 1 (Strongly Disagree) to 4 (Strongly Agree), so higher means indicate higher levels of agreement.

The participants also tended to agree with the item related to college life is stressful $(M=3.39, S D=0.52)$, the item on my level of stress increases significantly before exams $(M=3.18, S D=0.73)$, and the item expectations to excel in classes causes additional stress $(M=3.14, S D=0.76)$. The statement with which participants disagreed most strongly was the item related to I struggle to balance my personal stress and my academic stress $(M=2.47, S D=0.80)$. The participants had relatively weak levels of agreement with the items of my personal stressors affect my academic performance $(M=2.57, S D=0.80)$, stress from my academics affects my concentration while studying $(M=2.66, S D=0.77)$, and procrastination plays a big part in my stress level $(M=2.68, S D=0.94)$.

Based on these responses, the answer to the second research question of the study was the college students' perceptions of coping mechanisms.

Table 3. College students' perceptions of coping mechanisms

\begin{tabular}{lll}
\hline Variable & $M$ & $S D$ \\
\hline Listen to Music & 3.08 & 0.70 \\
Socialize with friends/ family & 2.88 & 0.83 \\
Sit alone in a quiet place & 2.83 & 0.81 \\
Exercise & 2.78 & 0.83 \\
Read the Bible/ Pray & 2.58 & 0.83 \\
Take a shower or bath & 2.58 & 0.89 \\
Take a nap & 2.51 & 0.99 \\
Clean house/ room & 2.48 & 0.95 \\
Watch TV & 2.37 & 0.95 \\
Chew fingernails & 1.81 & 1.08 \\
Read a book & 1.78 & 0.77 \\
Write in a journal & 1.71 & 0.84 \\
Cry excessively & 1.64 & 0.89 \\
Drink alcohol & 1.17 & 0.47 \\
Smoke/Vape & 1.07 & 0.31 \\
\hline Note. (N= & $120)$. &
\end{tabular}

Note. $(\mathrm{N}=120)$. Items were rated on a 4-point Likert-type scale ranging from 1 (Never) to 4 (Always), so a higher mean indicates a higher level of agreement. 
The participants also tended to agree with the item related to listen to music $(M=3.08, S D=0.70)$, the item on socialize with friends/family $(M=2.88, S D=0.83)$, and the item on sit alone in a quiet place $(M=2.83$, $S D=0.81)$. The statement with which participants disagreed most strongly was the item related to smoke/vape $(M=1.07, S D=0.31)$. The participants had relatively weak levels of agreement with the items of drink alcohol $(M=1.17, S D=0.47)$, cry excessively $(M=1.64, S D=0.89)$, and write in a journal $(M=1.71$, $S D=0.84)$.

\subsection{Summary of Results}

The research questions for this study were, "What are college students' perceptions of stress?" and "What are college students' perceptions of coping mechanisms?" The results indicated the perceptions of college students relating to both stress and coping mechanisms. First, students perceived that college life in general was stressful. The close majority of responses reflected that students perceived stress to solely pertain to right before an exam, a heavy academic workload, and expectations to excel in classes. Next, the majority of participants said they listen to music or socialize with friends and family to use as coping mechanisms when feeling stressed. Lastly, the study showed that college students perceived college in general to be stressful and were capable to utilize healthy coping mechanisms in response. The following section compares the results to the literature review used to formulate this study and recommendations for further studies.

\section{Analysis}

\subsection{Discussion of Findings}

The review of the literature revealed that academic stressors and personal stressors are caused by various factors and the coping mechanisms differ. A survey conducted by the American College Health Association (ACHA, 2017) found that $41.5 \%$ of college students reported having a "more than average" level of stress, and $12.5 \%$ reported having a "tremendous" level of stress (p. 16). The literature review also suggested that college students are vulnerable to stress and tend to have poor coping habits. As stated in the literature review, Coiro et al. (2017) reported that coping mechanisms "have been identified as a key mechanism linking perceived stress and stressful life events to the development of mental health problems" (p. 177). Students reporting higher levels of psychological stress were the individuals more likely to cope negatively with tobacco or poor diet. Lastly, researchers found that students were able to acknowledge that stress tends to affect multiple areas of their lives and by bettering one area, their stress level as a whole will decrease.

\subsection{Discussion of Findings in Relation to Research Questions}

\section{RQ 1: What are college students' perceptions of stress?}

The study agreed with the research findings that college students perceive to have high levels of stress. This study revealed that students believe college life in a general sense is stressful, especially when it revolves around academic performance and managing the workload between different classes. There was not a major shift in deviation from the statement with the highest agreeance to the statement with the lowest agreeance. Overall, college students perceived to have increased levels of stress pertaining to their academics and acknowledged that other factors such as procrastination and personal factors unrelated to academics cause their stress levels to rise. 


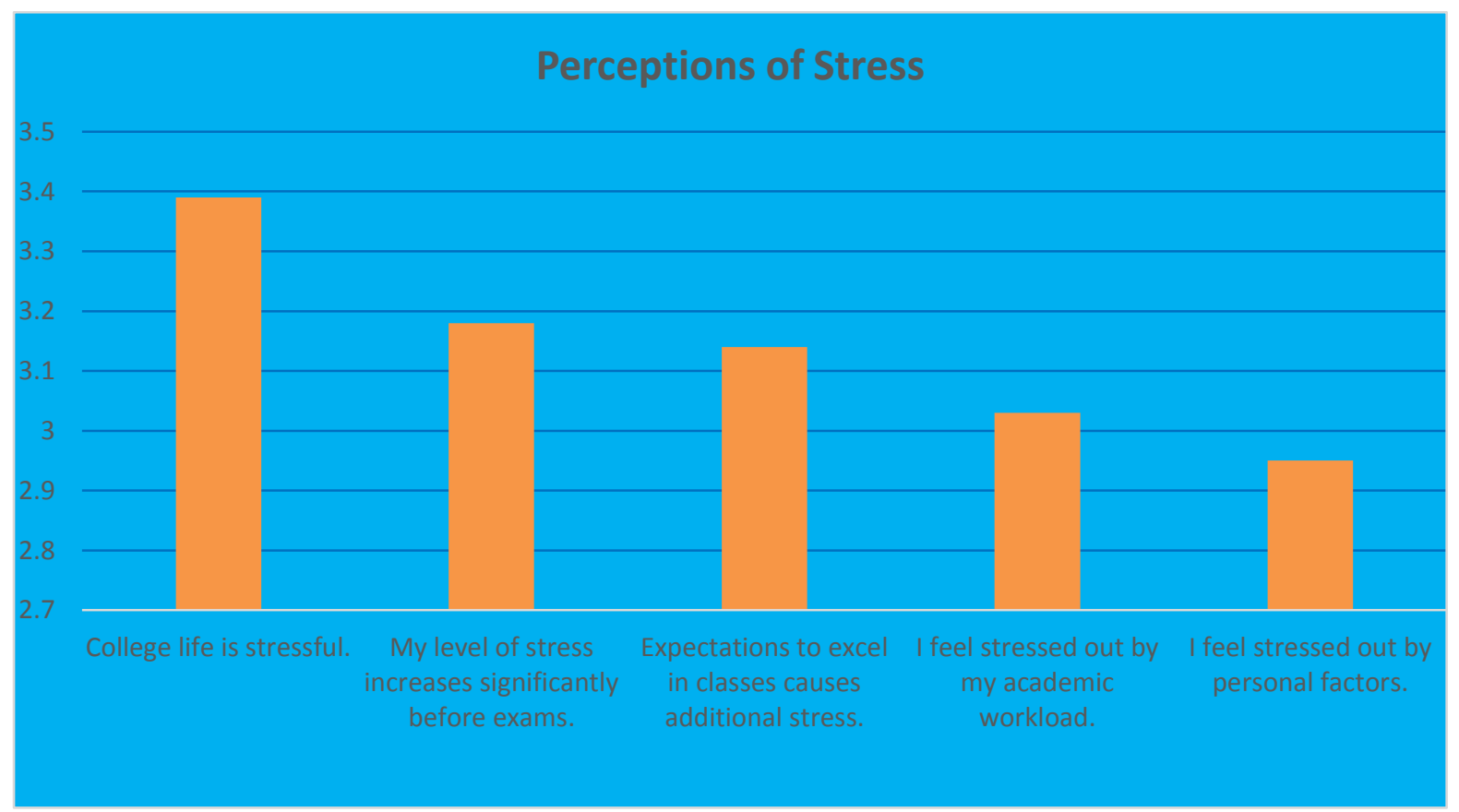

Figure 1. Students' perceptions of stress

Mean on a 4-point Likert -type scale. $\mathrm{N}=120$.

RQ 2: What are college students' perceptions of coping mechanisms?

After the literature review, the researchers concluded that college students were inclined to utilize "negative" coping mechanisms like tobacco, alcohol, physical inactivity, and poor diet. This study, however, found that college students tend to utilize "healthy" coping mechanisms like listening to music, socializing with friends or family, sitting alone in a quiet place, exercising, and reading the Bible or praying. There is a limitation to comparing research found in the literature review to this study because not all sources used in the literature review were specified to private Christian population groups. Overall, perceptions of different coping mechanisms and the beneficial use of coping mechanisms were acknowledged.

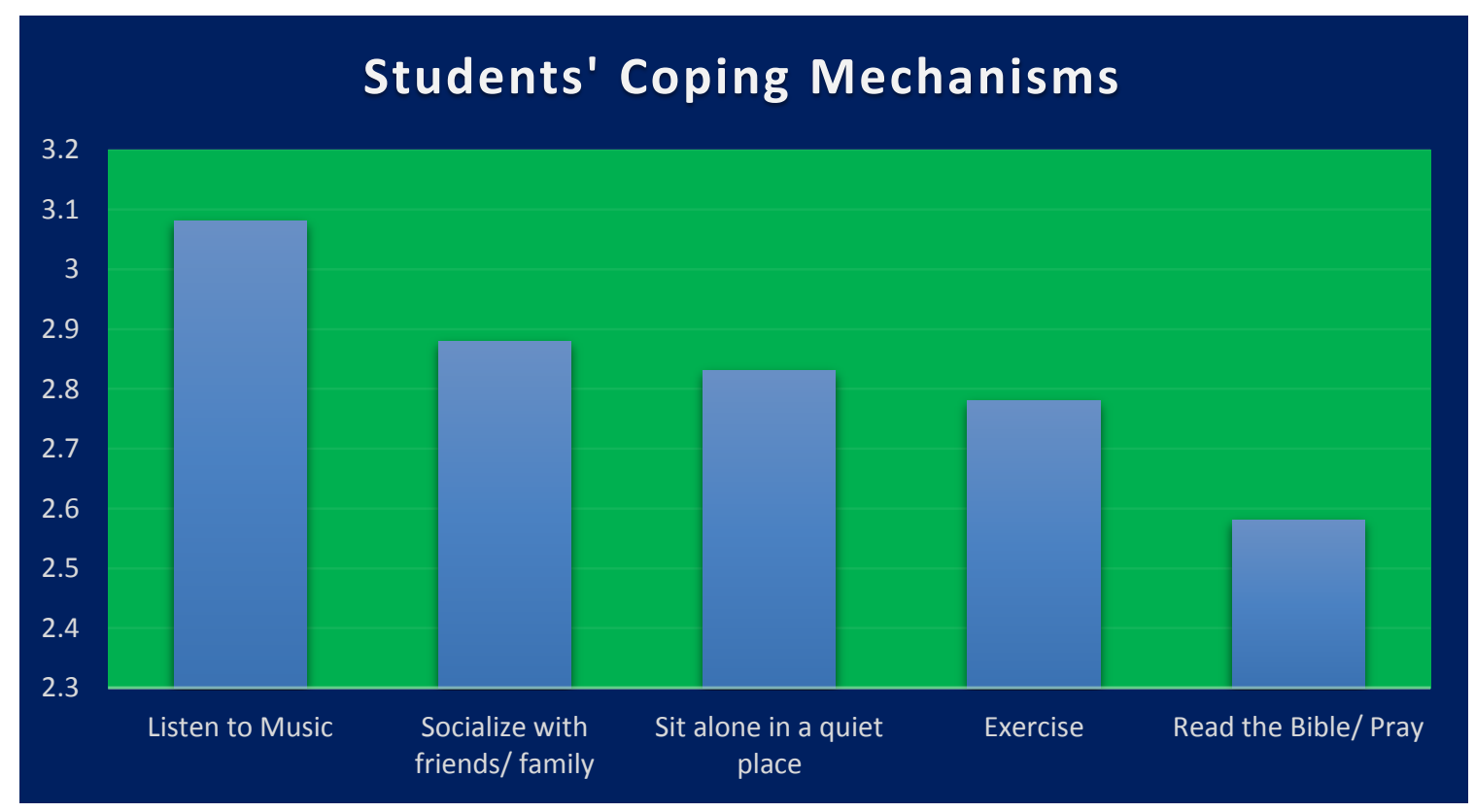

Figure 2. Students' perceptions of coping mechanisms

Mean on a 4-point Likert -type scale. $\mathrm{N}=120$. 


\section{Limitations}

One of the limitations of this study was the small sample size. Out of the population of nearly 2,000 students, only 120 students were surveyed. Additionally, all participants were college students, which reduces the variety of opinions and perspectives. The homogeneity and demographics of a faith-based college were another limitation in this study. The survey tool was new and did not have established reliability and validity. The data was only collected outside of the Dining Commons on one day from 10:45 a.m. to 1:00 p.m., which may not have taken into consideration those who generally only eat at the Dining Commons for dinner. In addition, the college was hosting a career fair on campus during the time the research was conducted, which may have reduced the number of students who came to the Dining Commons for lunch. The survey did not include ethnicity as part of the demographics, thus the researchers were unable to identify trends among ethnicity groups. In addition, the survey only gave the participants the options to choose male or female for gender, which inadvertently excluded the participants who did not identify as either male or female. Despite these limitations, an adequate understanding of the college students' perceptions of stress and coping mechanisms was gained.

\section{Implications}

The conclusions of this study may offer insight into college students' stress and how they cope with that stress. Educators and health care professionals will inevitably encounter college students and having an improved understanding of their stressors could illicit better intervention. Additionally, the results of this study suggest that students may already have an understanding of stress and coping mechanisms.

\section{Recommendations}

As mentioned before, researchers found a gap in research concerning perceptions of stress and coping mechanisms among Christian college students. Further research on this topic is warranted given that the researchers were only able to gather data from 120 students from a Christian college. Further research will give a more complete and accurate view of student's perceptions of stress and coping mechanisms at Christian colleges. Surveying students in different locations on campus or various other Christian college campuses would be beneficial to compare different perceptions based on the college. This study would have benefited from placing ethnicity as an option in the demographics to give a more detailed picture of the variety of participants in this study.

\section{Conclusion}

College is a stressful time for many students. It is impossible to completely eliminate all stress from college students, but there are many ways that students may cope with the stress they face. In this research study, data was gathered to assess students' perceptions of the stress they face, as well as their means of coping with said stress. Most of the participants agreed that college life is stressful and that their level of stress increases before exams. In addition, the majority agreed that expectations to excel academically cause them additional stress. The majority of participants listen to music as a coping mechanism in addition to socializing with friends and family.

\section{References}

American College Health Association. (2017). National college health assessment. Retrieved from https://www.acha.org/documents/ncha/NCHA-II_FALL_2017_REFERENCE_GROUP_EXECUTIVE_SU MMARY.pdf

Centers for Disease Control and Prevention. (2017). Coping with stress. Retrieved from https://www.cdc.gov/features/copingwithstress/index.html

Coiro, M., Bettis, A., \& Compas, B. (2017). College students coping with interpersonal stress: Examining a control-based model of coping. Journal of American College Health, 65(3), 177-186. https://doi.org/10.1080/07448481.2016.1266641

Deasy, C., Coughlan, B., Pironom, J., Jourdan, D., \& McNamara, M. (2015). Psychological distress and lifestyle of students: Implications for health promotion. Health Promotion International, 30(1), 77-87. https://doi.org/10.1093/heapro/dau086

Dexter, L., Huff, K., Rudecki, M., \& Abraham, S. (2018). College students' stress coping behaviors and perception of stress-effects holistically. International Journal of Studies in Nursing, 3(2), 1-6. https://doi.org/10.20849/ijsn.v3i2.279

Eyong, D. (2013). The effects of stress level and emotional intelligence on academic achievement of nursing students. DNA Reporter, 38(4), 9. $\quad$ Retrieved from http://link.galegroup.com.bcezproxy.bethelcollege.edu/apps/doc/A351948419/PPNU?u=nd_bethel\&sid=PP 
NU\&xid $=085 \mathrm{f} 421 \mathrm{~b}$

Holinka, C. (2015). Stress, emotional intelligence, and life satisfaction in college students. College Student Journal, 49(2), 300-311. Retrieved from https://eric.ed.gov/?id=EJ1095697

Hubbard, K., Reohr, P., Tolcher, L., \& Downs, A. (2018). Stress, mental health symptoms, and help-seeking in college students. Psi Chi Journal of Psychological Research, 23(4), 293-305. https://doi.org/10.24839/2325-7342.JN23.4.293

Jennings, R., Henderson, C., Erla, M., Abraham, S., \& Gillum, D. (2018). Stress coping behaviors of faith-based college non-student athletes vs. student-athletes. College Student Journal, 52(2), 245-257. Retrieved from https://eric.ed.gov/?id=EJ1180294

National Institute for Mental Health. (2016). 5 Things you should know about stress (Report No. OM 16-4310). Bethesda, MD: National Institute of Mental Health. Retrieved from https://www.nimh.nih.gov/health/publications/stress/5thingsshldknowaboutstress-508-03132017_142898.pd $\mathrm{f}$

Peer, J., Hillman, S., \& Van Hoet, E. (2015). The effects of stress on the lives of emerging adult college students: An exploratory analysis. Adultspan Journal, 14(2), 90-99. https://doi.org/10.1002/adsp.12007

Ribeiro, I., Pereira, R., Freire, I., de Oliveira, B., Casotti, C., \& Boery, E. (2018). Stress and quality of life among university students: A systematic literature review. Health Professions Education, 4, 70-77. https://doi.org/10.1016/j.hpe.2017.03.002

Saleh, D., Camart, N., \& Romo, L. (2017). Predictors of stress in college students. Frontiers in Psychology, 8(19), 1-8. https://doi.org/10.3389/fpysg.2017.00019

Shatkin, J., Diamond, U., Zhao, Y., DiMeglio, J., Chodaczek, M., \& Bruzzese, J. (2016). Effects of a risk and resilience course on stress, coping skills, and cognitive strategies in college students. Teaching of Psychology, 43(3), 204-210. https://doi.org/10.1177/0098628316649457

\section{Copyrights}

Copyright for this article is retained by the author(s), with first publication rights granted to the journal.

This is an open-access article distributed under the terms and conditions of the Creative Commons Attribution license (http://creativecommons.org/licenses/by/4.0/). 